\title{
Spontaneous alternation in Mesocricetus auratus: Age differences'
}

\author{
ROBERT J. KIRKBY, PSYCHIATRIC RESEARCH UNIT, ROZELLE, N.S.W., AUSTRALIA
}

GLENN H. LACKEY, UNIVERSITY OF OREGON

The spontaneous alternation performances of three groups of hamsters, 20, 50, and 150 days old, were compared. $A$ positive association was found between age and rate of alternation. These findings were interpreted as additional evidence of the relationship between the ability of an animal to acquire and retain information and the rate at which it alternates. It was tentatively suggested that the apparent differences in alternation rates of hamsters, ferrets, and rats could reflect species differences in learning and remembering.

Given successive trials in a $T$ or a $Y$ maze a rat will typically alternate responses; that is, it will enter one arm of the maze on the initial trial and the alternative on the second. This phenomenon, termed "spontaneous alternation," has been observed in the rat (Dember \& Fowler, 1958), the marsupial possum (Tilley et al, 1966), the ferret (Hughes, 1965), and the human (Schultz, 1964). Spontaneous alternation is not typical for submammalian animals; however, a similar type of behavior, "delayed compensatory responding" (Dingle, 1965) has been observed in several of these species (Hayes \& Warren, 1963; Dingle, 1964, 1965; Kupfermann, 1966). Pharmacological (Parkes, 1965), developmental (Kirkby \& Kirkby, 1968), and lesion studies (Kirkby et al, 1967) have indicated a close relationship between the ability of an animal to acquire and retain information and the rate at which it spontaneously alternates. Similarly, recent findings have suggested that delayed compensatory responding is dependent upon learning and memory processes (Dingle, 1964, 1965; Kupfermann, 1966).

In an investigation of the association between age and spontaneous alternation in the rat, it was found that alternation performance developed with maturity (Kirkby, 1967). The purpose of the present study was to confirm and extend these findings with another species of rodent, the golden hamster. It was predicted that in the hamster, as in the rat, spontaneous alternation would increase as a function of maturation. Subjects

The Ss, 75 male hamsters (Mesocricetus auratus) from the University of Oregon Biology Colony, were tested in three groups, each of 25 . At the time of testing the $\mathrm{Ss}$ in each group were respectively 20,50, and 150 days old. All Ss were maintained in group cages with free access to food and water.

\section{Apparatus}

The apparatus were three $\mathrm{T}$ mazes proportioned to the sizes of the Ss. The maze for the 20-day-old group had arms $24 \mathrm{~cm}$ long, $10 \mathrm{~cm}$ deep, and $7.5 \mathrm{~cm}$ wide. The 50-day-old Ss were tested in a maze with arms
$30 \mathrm{~cm}$ long, $12.5 \mathrm{~cm}$ deep, and $10 \mathrm{~cm}$ wide, and the 150-day-old Ss in a maze with arms $45 \mathrm{~cm}$ long, $15 \mathrm{~cm}$ deep, and $15 \mathrm{~cm}$ wide. The apparatus were painted grey and were roofed with wire mesh lids. In each case the stem of the $T$, serving as a startbox, was separated from the rest of the apparatus by a guillotine door.

\section{Procedure}

The maze was placed on a table so that the choice point was directly below a shaded, $100 \mathrm{~W}$ electric light. Each $\mathrm{S}$ was given two trials. A trial commenced when the $S$ was placed in the startbox. Three sec later the guillotine door was raised and the $S$ allowed to enter the maze. A four-footed entry into either arm of the $T$ terminated the trial. Within three to five sec the $S$ was returned to the startbox for the second trial.

Results

The alternation rates corrected for turning preferences demonstrated in the initial trials (Douglas, 1966), were tested against chance by $x^{2}$. Although the 20-dayold hamsters alternated randomly (adjusted rate $=$ $66.2 \%$ ), the older hamsters alternated significantly above chance (50-day-old, adjusted rate $=79.7 \%, \chi^{2}=$ 7.8, $\mathrm{df}=1, \mathrm{p}<.01$, two-tailed; 150 -day-old adjusted rate $=92.8 \%, x^{2}=16.0, d f=1, p<.001$, two-tailed). The alternation rate of the 150-day-old hamsters was significantly higher than that of the 20-day-old animals $\left(x^{2}=3.7, \mathrm{df}=1, \mathrm{p}<.03\right.$, two-tailed). The performance of the 50-day-old group did not differ significantly from either of the other groups. A positive association was found between age and rate of alternation $(C=0.26$, $\mathrm{df}=2, \mathrm{p}<.05$, one-tailed). Controlled observation indicated no differences between groups in latencies to leave the startbox.

\section{Discussion}

The lack of differences between groups to leave the startbox suggests that the lowered alternation rates of the younger hamsters were not due to increased emotionality. Investigations with the rat indicating that fear of novel environmental stimuli develops with age (Candland \& Campbell, 1962) support this view. It has been found, in a variety of species, that exploratory activity is generally higher in subadult than adult animals (Thompson \& Heron, 1954; Glickman \& Sroges, 1966). This indicates that the alternation deficits were not the result of a lessened exploratory drive.

We suggest that the differences in alternation between the youngest and oldest hamsters were due to differences in their abilities to acquire and retain the sen- 
sory cues necessary to differentiate one arm of the $T$ maze from the other. It has been shown that the ability to acquire and retain information develops with maturation (Scott, 1962; Vince, 1963). The differences in spontaneous alternation observed in the present study appear to reflect this development.

The $92.8 \%$ rate of alternation for the adult hamsters was similar to the $95 \%$ reported for the ferret (Hughes, $1965)$, but above the $81-82 \%$ generally reported for the rat (Dember \& Fowler, 1958; Douglas, 1966). Further investigations will be necessary to establish whether these apparent differences are significant. However, any variations in the alternation performances of these animals could indicate species differences in the ability to learn and remember. Recent findings suggesting that the problem solving ability of the ferret is superior to that of the rat are consistent with such a possibility (Doty et al, 1967).

\section{References}

CANDLAND, D. K., \& CAMPBELL, B. A. Development of fear in the rat as measured by behavior in the open field. J. comp. physiol. Psychol., 1962, 55, 593-596.

DEMBER, W. N., \& FOWLER, H. Spontaneous alternation behavior. Psychol. Bull., 1958, 55, 412-428.

DINGLE, H. Further observations on correcting behavior in boxelder bugs. Anim. Behav., 1964, 12, 116-124.

DINGLE, H. Turn alternation by bugs on causeways as a delayed compensatory response and the effects of varying visual inputs and length of straight path. Anim. Behav., 1965, 13, 171-177.

DOTY, B. A., JONES, C. N., \& DOTY, L. A. Learning-set formation by mink, ferrets, skunks, and cats. Science. 1967, 155, 1579-1580.

DOUGLAS, R. J. Cues for spontaneous alternation. J. comp. physiol. Psychol., 1966, 62, 171-183.
GLICKMAN, S. E., \& SROGES, R. W. Curiosity in zoo animals. Behaviour, 1966, 26, 151-188.

HAYES, W. N., \& WARREN, J. M. Failure to find spontaneous alternation in chicks. $J$. comp. physiol. Psychol., 1963, 56, 575-577.

HUGHES, R. N. Spontaneous alternation and response to stimulus change in the ferret. $J$. comp. physiol. Psychol, 1965, 60, 149-150.

KIRKBY, R. J. A maturation factor in spontaneous alternation. Nature, $1967,215,784$.

KIRKBY, R. J., STEIN, D. G., KIMBLE, R. J., \& KIMBLE, D. P. Effects of hippocampal lesions and duration of sensory input on spontaneous alternation. J. comp. physiol. Psychol., 1967, 64, 342-345.

KIRKBY, R. J., \& KIRKBY, J. E. Spontaneous alternation as a function of early environmental experience in the rat. Unpublished manuscript. N. S. W. Department of Health Library, 1968.

KUPFERMANN, I. Turn alternation in the pill bug (armadilidiumvulgare). Anim. Behav., 1966, 14, 68-72.

PARKES, M. W. An examination of central actions characteristic of scopolamine: Comparison of central and peripheral activity in scopolamine, atropine and some synthetic basic esters. Psychopharmacologia, 1965, 7, 1-19.

SCHULTZ, D. P. Spontaneous alternation behavior in humans: Implications for psychological research. Psychol. Bull., 1964, 62, 394-400.

SCOTT, J. P. Critical periods in behavioral development. Science, $1962,138,949-958$.

THOMPSON, W. R., \& HERON, W. The effects of early restriction on activity in dogs. J. comp. physiol. Psychol., 1954, 47, 77-82.

TILlEY, M. W., DOOLITTLE, J. H., \& MASON, D. J. Spontaneous alternation in the Virginia opossum. Psychol. Rep., 1966, 19, 593-594.

VINCE, M. A. Developmental changes in learning capacity. In W. H. Thorpe and O. L. Zangwill (Eds.), Current problems in animal behavior. Cambridge University Press, 1963, pp. 225-247.

Note

1. This investigation was partially supported by USPHS Grant MH 08545-03 to D. P. Kimble and by research funds to R. J. Kirkby from the N. S. W. Department of Public Health, with whose permission the paper is published. 